\title{
Calcium and vitamin D supplementation with 3-year denosumab treatment is beneficial to enhance bone mineral density in postmenopausal patients with osteoporosis and rheumatoid arthritis
}

This article was published in the following Dove Press journal:

Therapeutics and Clinical Risk Management

\author{
Takako Suzuki' \\ Yukio Nakamura ${ }^{1,2}$ \\ Hiroyuki Kato' \\ 'Department of Orthopaedic \\ Surgery, Shinshu University School \\ of Medicine, Matsumoto, Japan; \\ ${ }^{2}$ Department of Orthopaedic Surgery, \\ Showa Inan General Hospital, \\ Komagane, Japan
}

Background: This 3-year retrospective study compared the outcomes of bisphosphonatepretreated denosumab therapy with or without vitamin D and calcium supplementation in postmenopausal osteoporosis (OP) patients with rheumatoid arthritis (RA).

Materials and methods: Fifty-eight patients under long-term denosumab treatment were divided into groups without (denosumab group; 31 cases) or with (combination group; 27 cases) vitamin D and calcium supplementation. The bone markers of BAP, TRACP-5b, and urinary NTX were measured at baseline and every year for 3 years. We also evaluated bone mineral density (BMD) of the lumbar 1-4 vertebrae (L-BMD) and bilateral total hips (H-BMD) at the same time points. Results: There were no significant differences in the percent changes of serum albumin-corrected calcium between the groups. The percent change in TRACP-5b was significantly higher in the combination group at 2 years. Serum 25-hydroxyvitamin D status was persistently high during therapy in both groups, with significant percent increases over baseline at 2 and 6 months in both groups and at 24 months in the combination group. The percent increase from baseline of serum zinc was significantly higher at 3 years in the combination group over the denosumab group. L-BMD and H-BMD were significantly increased at every time point for 3 years vs pretreatment levels in both groups and were significantly higher in the combination group at all time points.

Conclusion: Compared with denosumab monotherapy, the combination group displayed significantly increased serum zinc, L-BMD, and H-BMD at 3 years in OP patients with RA. Thus, calcium and vitamin D supplementation may be beneficial to enhance BMD gains, but not necessarily 25-hydroxyvitamin D status, in patients with OP and RA under denosumab.

Keywords: $25(\mathrm{OH}) \mathrm{D}$, bone mineral density, bone-related minerals, denosumab, osteoporosis, rheumatoid arthritis

\section{Introduction}

Osteoporosis (OP) is a widespread condition in which diminished bone quality is caused by losses in bone microarchitecture and bone mass. ${ }^{1,2}$ Reduced bone strength in OP patients may lead to increased fracture risk, which constitutes the major cause of mortality and morbidity in OP. ${ }^{3}$

Rheumatoid arthritis (RA) is an autoimmune disease with hallmark joint inflammation and destruction. OP is a major complication of RA, ${ }^{4}$ with $15 \%-20 \%$ of RA patients having
Correspondence: Yukio Nakamura Department of Orthopaedic Surgery, Shinshu University School of Medicine, Asahi 3-I-I, Matsumoto 390-862I, Japan Tel +8I 263372659

Fax +8I 263358844

Email yxn 14@aol.jp 
afflictions of the hip and spine. ${ }^{5,6}$ Inflammation plays key roles in RA activity, bone resorption, and OP progression. ${ }^{7}$

Vitamin D figures prominently in bone formation and remodeling. ${ }^{8,9}$ Although maintaining adequate levels of serum vitamin $\mathrm{D}$ is necessary to protect against bone fracture, ${ }^{10,11}$ vitamin $\mathrm{D}$ deficiency is a worldwide health concern. ${ }^{8}$ Tan et al very recently reported that reduced levels of 25-hydroxyvitamin $\mathrm{D}(25(\mathrm{OH}) \mathrm{D})$ might indicate a high risk of secondary OP in RA patients. ${ }^{12}$ However, the status and changes of 25(OH)D during osteoporotic treatment for OP with RA are largely unknown, with no data available on denosumab therapy with or without vitamin D and calcium supplementation.

Regarding OP treatment, bisphosphonates (BPs) and denosumab, a fully human monoclonal antibody against receptor activator of nuclear factor $\mathrm{\kappa B}$ ligand, are common therapeutic agents. Although BP therapy is generally the standard of care for OP by inhibiting osteoclast activity,,$^{13}$ denosumab is also considered useful for primary as well as secondary OP. Denosumab treatment for 10 years has been associated with low rates of adverse events, low fracture incidence, and sustained increases in bone mineral density (BMD). ${ }^{14}$

We earlier demonstrated that calcium and vitamin D supplementation of denosumab represented a useful treatment option for OP with RA, imparting additive effects on increases in bilateral total hip BMD (H-BMD) over 12 months in the absence of fracture and hypocalcemia. ${ }^{15}$ Thus, we have hypothesized that long-term denosumab treatment can also enhance BMD and bone turnover markers and prevent fracture in OP with RA, especially in cases of prolonged BP pretreatment.

This 3-year retrospective study compared the differences in outcomes with or without calcium and vitamin D supplementation in OP patients with RA under denosumab.

\section{Materials and methods}

The inclusion criteria of this 3-year retrospective investigation were OP patients with low (ie, less than $-2.5 \mathrm{SD}$ ) H-BMD and/or lumbar 1-4 BMD (L-BMD) with RA. The exclusion criteria were chronic renal failure (estimated glomerular filtration rate $<40 \mathrm{~mL} / \mathrm{min} / 1.73 \mathrm{~m}^{2}$ ), disorders of bone metabolism or diabetes mellitus that could affect OP, and fracture within 12 months before the study. OP was diagnosed based on the revised criteria established by the Japanese Society of Bone and Mineral Research. ${ }^{16}$ RA was diagnosed and treated following the $2010 \mathrm{ACR} /$ European League Against Rheumatism (EULAR) classification system. ${ }^{17}$

We recruited 58 Japanese female OP patients with RA of low-to-moderate disease activity $(2.6<$ disease activity score 28 [DAS28]-C-reactive protein $[\mathrm{CRP}] \leq 5.1$ ) at our hospital between 2014 and 2018 (Table 1). All subjects had taken BPs for at least 5 years prior to the start of this study. The patients were retrospectively divided into those with (combination group; 27 cases) or without (denosumab group; 31 cases) vitamin $D$ and calcium supplementation and were matched according to age, gender, body mass index, BP pretreatment period, and RA duration and activity. Alendronate $(\mathrm{ALN})$, risedronate, and minodronate had been prescribed in various regimens as long-term BP pretreatment. The effects of individual BP drugs were not addressed since they were routinely switched if deemed ineffective.

Each patient received denosumab $(60 \mathrm{mg}$, subcutaneously) once every 6 months in both groups. Subjects in the combination group took vitamin D and calcium supplementation tablets (precipitated calcium carbonate: $762.5 \mathrm{mg}$, cholecalciferol: $200 \mathrm{IU}$, magnesium carbonate: $59.2 \mathrm{mg}$ ) twice daily during denosumab administration. All treatments were substituted from BPs to denosumab prior to study commencement for baseline measurements.

All serologic testings were conducted just before denosumab (baseline) and at 1, 2, and 3 years of treatment from frozen samples by commercially available kits, including that for matrix metalloproteinase-3 (MMP-3) (Kyowa Pharma Chemicals, Toyama, Japan). We also examined changes in DAS28-CRP, simplified disease activity index (SDAI), and health assessment questionnaire disability index (HAQ-DI) to determine the RA status of all patients prior to the start of the study. All data were expressed as the mean \pm standard error (SE).

Serum bone alkaline phosphatase (BAP) was examined as a bone formation marker using a chemiluminescent enzyme immunoassay. Serum tartrate-resistant acid phosphatase (TRACP)-5b and urinary N-terminal telopeptide of type I collagen (NTX) (Osteomark, Ostex International, Seattle, WA, USA) were used as markers of bone resorption using ELISA. Serum whole parathyroid hormone 1-84 (PTH) was measured by immunoradiometric assays. Serum $1,25(\mathrm{OH})_{2} \mathrm{D}_{3}$ was determined by immunoradiometric assays. Serum 25(OH)D was determined by solid-phase radioimmunoassays. Serum and urine were collected in a fasting state after omitting the first morning samples between 8:30 am and 11:00 am. Immunoassays were carried out by SRL, Inc. (Tokyo, Japan). Serum samples collected before and at 1, 2, and 3 years of denosumab treatment were maintained at $-80^{\circ} \mathrm{C}$ until bone turnover marker assessment at the end of the study.

BMD was determined using a dual-energy X-ray absorption fan-beam bone densitometer (Lunar Prodigy; 
Table I Patient characteristics at baseline

\begin{tabular}{|c|c|c|c|}
\hline Characteristics & Denosumab $(n=3 I)$ & Combination $(n=27)$ & $P$-value \\
\hline Age (years) & $68.7 \pm 1.2$ & $68.3 \pm 1.7$ & 0.8165 \\
\hline BMI $\left(\mathrm{kg} / \mathrm{m}^{2}\right)$ & $20.1 \pm 0.6$ & $20.4 \pm 0.4$ & $0.685 \mid$ \\
\hline Serum Ca (mg/dL) & $9.3 \pm 0.1$ & $9.2 \pm 0.1$ & 0.5852 \\
\hline Serum Phosphorus (mg/dL) & $3.6 \pm 0.3$ & $3.5 \pm 0.1$ & 0.6704 \\
\hline Serum BAP $(\mu g / L)$ & $13.2 \pm 0.6$ & $12.7 \pm 0.7$ & 0.6248 \\
\hline Serum PINP (ng/mL) & $37.7 \pm 2.9$ & $34.3 \pm 2.8$ & 0.4010 \\
\hline Serum TRACP-5b (mU/dL) & $307.2 \pm 24.6$ & $336.8 \pm 31.0$ & 0.4579 \\
\hline Urinary NTX (nmol BCE/mmol/CRE) & $29.3 \pm 2.4$ & $31.6 \pm 3.3$ & $0.576 \mathrm{I}$ \\
\hline Serum whole PTH (pg/mL) & $23.9 \pm 2.0$ & $25.1 \pm 2.7$ & 0.7086 \\
\hline Serum $\mathrm{I}, 25(\mathrm{OH})_{2} \mathrm{D}_{3}(\mathrm{pg} / \mathrm{mL})$ & $61.7 \pm 4.6$ & $55.9 \pm 3.7$ & 0.3374 \\
\hline Serum 25(OH)D (ng/mL) & $17.9 \pm 0.8$ & $20.1 \pm 1.6$ & 0.2276 \\
\hline Serum zinc $(\mu g / d L)$ & $56.6 \pm 1.5$ & $54.3 \pm 1.5$ & 0.4351 \\
\hline Serum iron $(\mu g / d L)$ & $73.3 \pm 6.7$ & $61.1 \pm 7.2$ & 0.2246 \\
\hline Serum magnesium $(\mathrm{mg} / \mathrm{dL})$ & $2.1 \pm 0.3$ & $2.1 \pm 0.04$ & 0.6829 \\
\hline Duration of BP use (years) & $7.3 \pm 0.9$ & $6.4 \pm 0.7$ & 0.4427 \\
\hline Methotrexate (mg/week) & $7.5 \pm 0.7$ & $6.8 \pm 0.6$ & 0.4601 \\
\hline Methotrexate (months) & $19.2 \pm 2.4$ & $20.3 \pm 2.2$ & 0.7527 \\
\hline Prednisolone (mg/day) & $4.7 \pm 0.2$ & $5.0 \pm 0.0$ & 0.1747 \\
\hline LI -4 BMD $\left(\mathrm{g} / \mathrm{cm}^{2}\right)$ & $0.692 \pm 0.02$ & $0.695 \pm 0.02$ & 0.9177 \\
\hline Total hip BMD $\left(\mathrm{g} / \mathrm{cm}^{2}\right)$ & $0.487 \pm 0.02$ & $0.494 \pm 0.02$ & 0.7622 \\
\hline DAS28CRP & $3.1 \pm 0.2$ & $3.0 \pm 0.2$ & 0.7813 \\
\hline SDAI & $12.3 \pm 1.8$ & $10.6 \pm 1.6$ & 0.4855 \\
\hline HAQ-DI & $0.4 \pm 0.1$ & $0.4 \pm 0.1$ & 0.9678 \\
\hline MMP3 (IU/mL) & $97.4 \pm 13.9$ & $98.0 \pm 14.1$ & 0.9763 \\
\hline
\end{tabular}

Note: Data are expressed as mean \pm standard error.

Abbreviations: $(\mathrm{OH}) \mathrm{D}$, hydroxyvitamin $\mathrm{D}$; BAP, bone alkaline phosphatase; $\mathrm{BCE}$, bone collagen equivalent; $\mathrm{BMD}$, bone mineral density; BMI, body mass index; BP, bisphosphonate; Ca, albumin-corrected calcium; CRE, creatinine; DAS28CRP, disease activity score 28 C-reactive protein; HAQ-DI, health assessment questionnaire disability index; MMP3, matrix metalloproteinase-3; NTX, type I collagen cross-linked N-telopeptide; PINP, procollagen type I amino-terminal propeptide; PTH, parathyroid hormone; SDAI, simplified disease activity index; TRACP-5b, tartrate-resistant acid phosphatase-5b.

GE Healthcare Bio-Sciences Corp., Piscataway, NJ, USA) at the L1-4 levels of the posteroanterior spine and bilateral total hips before treatment commencement and at 1,2 , and 3 years.

Bone turnover markers, whole PTH, $1,25(\mathrm{OH})_{2} \mathrm{D}_{3}$, serum albumin-corrected calcium $(\mathrm{Ca})$, phosphorus, zinc, iron, magnesium, and BMD were all measured at set time points for statistical comparisons. $25(\mathrm{OH}) \mathrm{D}$ were measured before treatment commencement and at 2, 6, 12, 18, 24, 30, and 36 months of therapy for statistical comparisons. Some factors, such as diet habits and ultraviolet exposure that could have influenced vitamin D status in both groups, were excluded during the study period. Differences in percent changes from baseline were calculated using Bonferroni correction with repeated ANOVA for multiple comparisons. Comparisons of markers between the groups were performed by Welch's $t$-test. ${ }^{18}$ The critical value for rejecting the null hypothesis was $P<0.05$. Data analyses were conducted with the BellCurve for Excel (Social Survey Research Information Co., Ltd., Japan).

This study was approved by the Institutional Ethical Review Board of Shinshu University School of Medicine, Japan, and conducted in adherence to the tenets of the Declaration of Helsinki (2014 revision). All participants provided written informed consent.

\section{Results}

Patient backgrounds were comparable between the denosumab and combination groups (Table 1).

Mean \pm SE age was $68.7 \pm 1.2$ years in the denosumab group and $68.3 \pm 1.7$ years in the combination group. The enrolled patients had undergone pretreatment with BPs for a mean duration of $7.3 \pm 0.9$ years in the denosumab group and $6.4 \pm 0.7$ years in the combination group. The mean doses 
of methotrexate and prednisolone in the denosumab and combination groups were $7.5 \pm 0.7$ and $4.7 \pm 0.2 \mathrm{mg} /$ week and $6.8 \pm 0.6$ and $5.0 \pm 0.0 \mathrm{mg} /$ day, respectively (Table 1 ).

All 58 subjects attended all scheduled visits over the 3-year observational period (Table 1).

\section{$\mathrm{Ca}$ and phosphorus levels}

There were no significant differences in the percent changes of $\mathrm{Ca}$ between the groups (Figure 1A). No remarkable differences in percent change from baseline were seen for either group or between groups for serum phosphorous (Figure 1B).

\section{Serum whole PTH and $\mathrm{I}, 25(\mathrm{OH})_{2} \mathrm{D}_{3}$}

The percent change of serum whole PTH was seen to decrease and return to the baseline in denosumab patients and was comparable between the groups (Figure 1C).

The percent change of serum $1,25(\mathrm{OH})_{2} \mathrm{D}_{3}$ tended to be decreased at 1 and 2 years and return to baseline at 3 years in both groups in a similar manner (Figure 1D).

\section{Serum bone-related minerals}

The percent change of serum zinc was significantly greater in the combination group than in the denosumab group at 3 years, with significant differences at each time point in the combination group and at 1 and 2 years in the denosumab group vs baseline (Figure 2A). There were no remarkable differences in serum iron between the groups, although a significant increase over baseline was observed at 3 years in the combination group (Figure $2 \mathrm{~B}$ ). The percent change of serum magnesium was comparable between the groups, with a significant difference at 3 years in the denosumab group compared with baseline (Figure 2C).

\section{Bone resorption markers}

The percent change of serum TRACP-5b was significantly lower than baseline for both groups during treatment. There was a significant difference at 2 years between the groups (Figure 3A). Regarding urinary NTX, no remarkable differences in percent change were seen with baseline for either group or between the groups (Figure 3B).

\section{Bone formation marker}

The percent change of serum BAP was comparably and significantly lower than baseline throughout the treatment period in both groups (Figure 3C).

\section{Serum 25(OH)D}

The percent change of serum 25(OH)D was persistently high and significantly greater than baseline at 2 and 6 months in both groups and at 24 months in the combination group. There were no notable differences between the groups (Figure 3D).
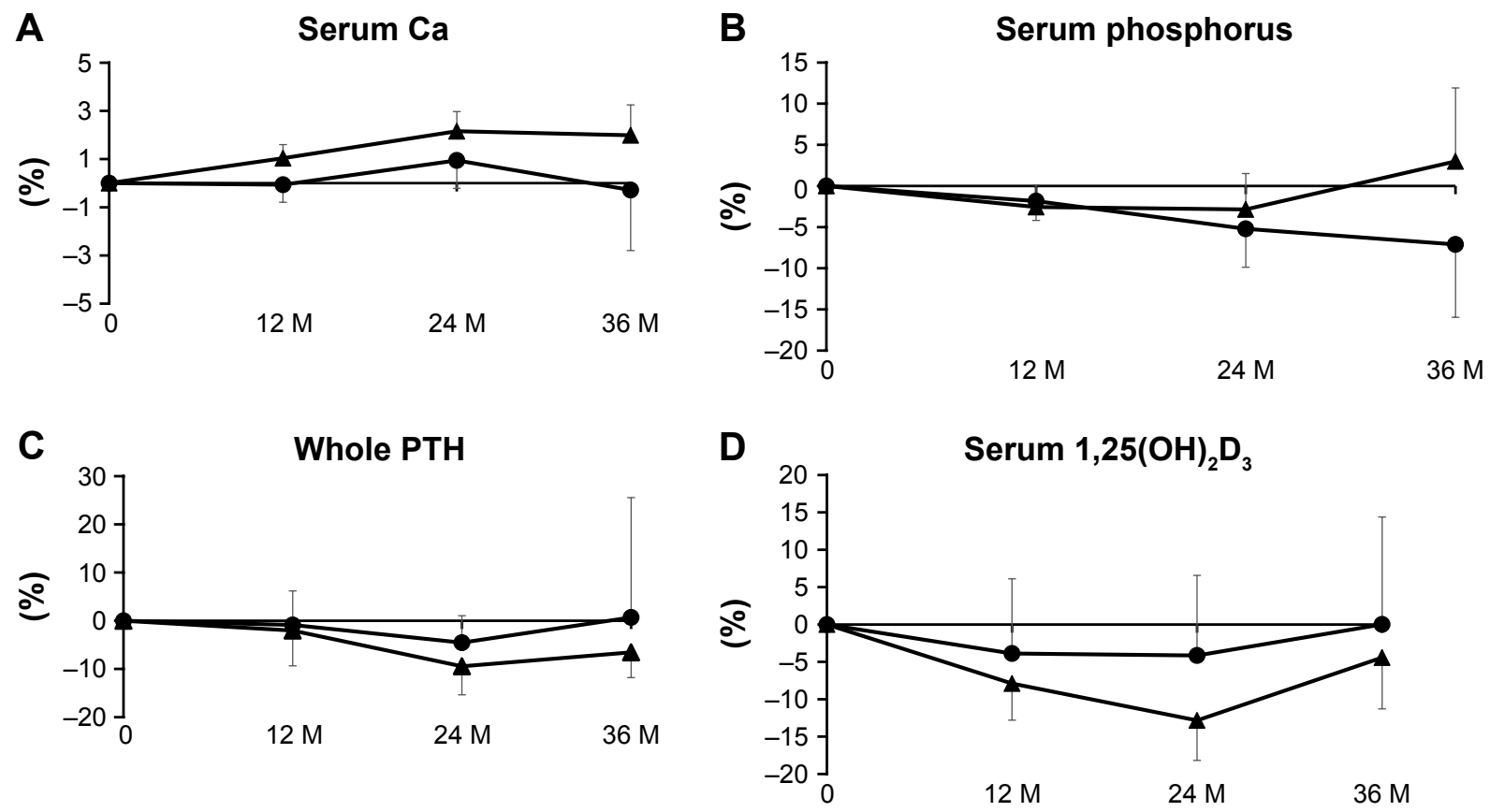

Figure I Percent changes of serum albumin-corrected calcium $(\mathrm{Ca})(\mathbf{A})$, serum phosphorus $(\mathbf{B})$, whole parathyroid hormone $(\mathrm{PTH})(\mathbf{C})$, and serum I,25(OH) $\mathrm{D}_{3}(\mathbf{D})$ at I2, 24, and 36 months (M). Circles show the denosumab group and triangles show the combination group. 

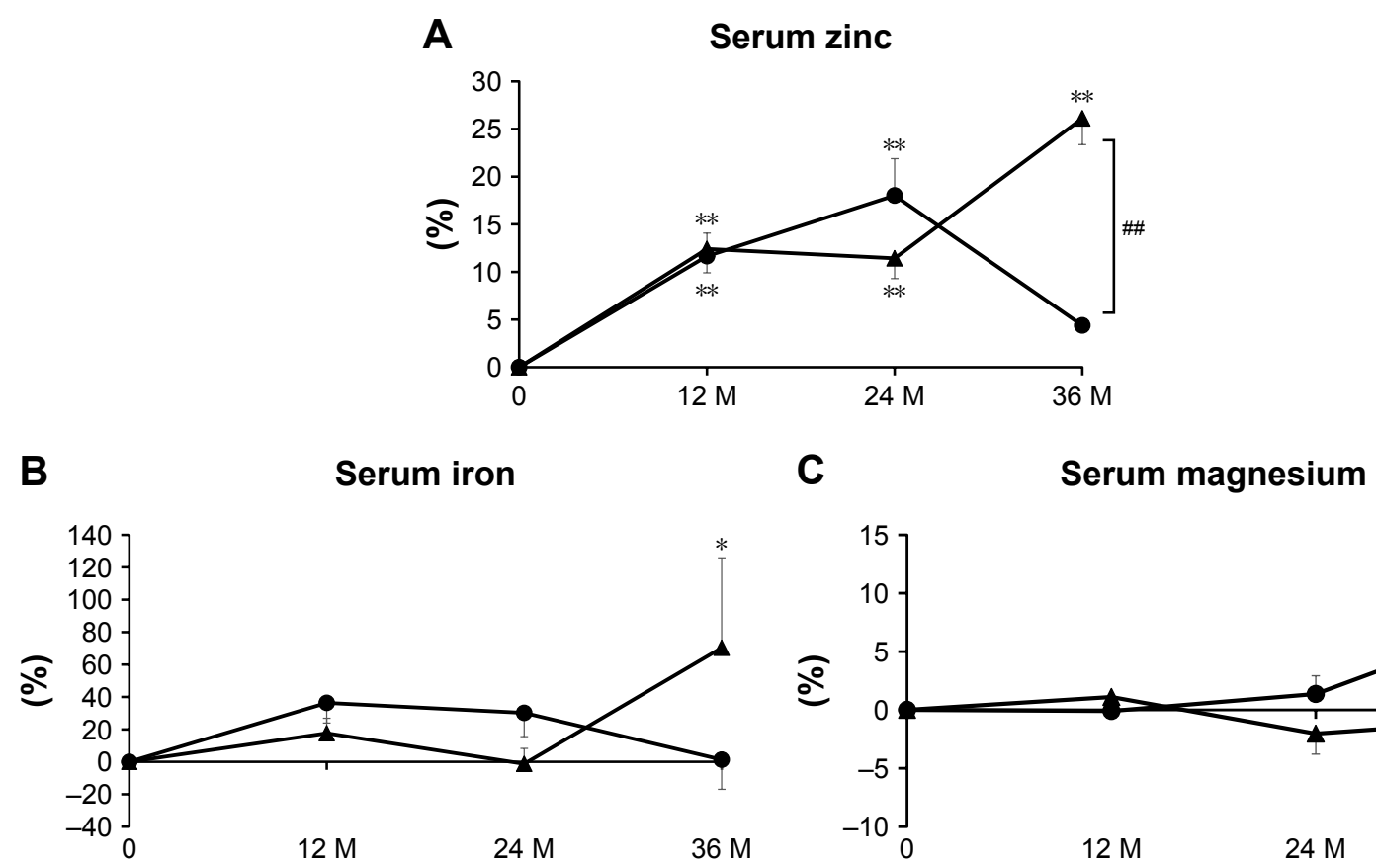

Figure 2 Percent changes of serum zinc $(\mathbf{A})$, serum iron $(\mathbf{B})$, and serum magnesium $(\mathbf{C})$ at 12 , 24, and 36 months (M).

Notes: Circles show the denosumab group and triangles show the combination group. Single and double asterisks indicate a significant difference $(P<0.0 \mathrm{I}$ and $P<0.05$, respectively) with baseline values.

\section{BMD}

\section{L-BMD and H-BMD}

The percent change of L-BMD increased steadily during treatment in the denosumab $(7.6 \%$ increase at 3 years $)$ and combination (11.3\% increase at 3 years) groups, with significant differences over baseline at every time point for both groups. L-BMD gains were significantly greater in the combination group at years 1, 2, and 3 (Figure 4A).
A

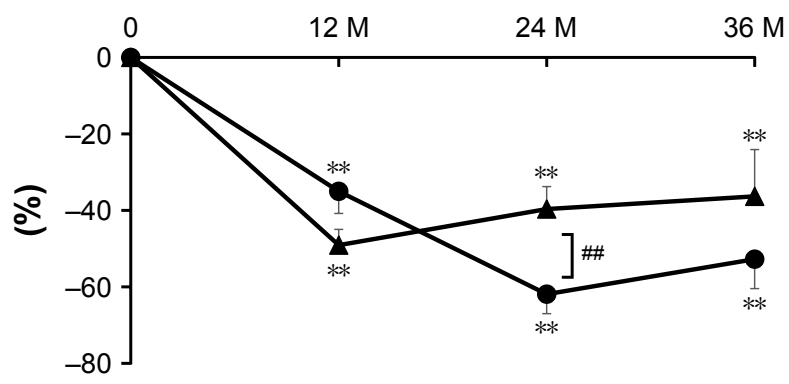

C

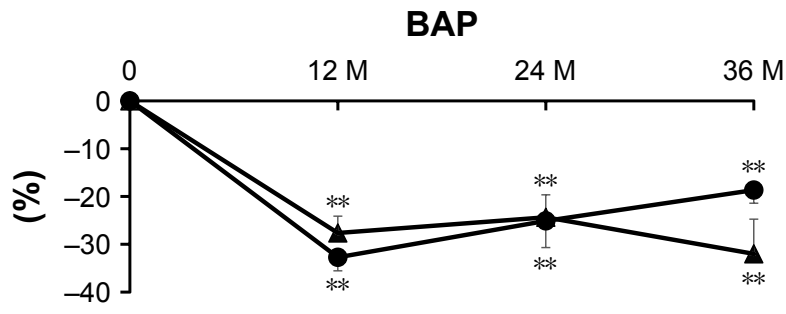

B

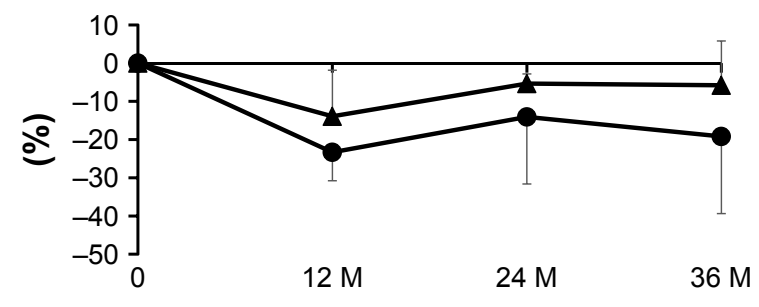

D

Serum 25(OH)D

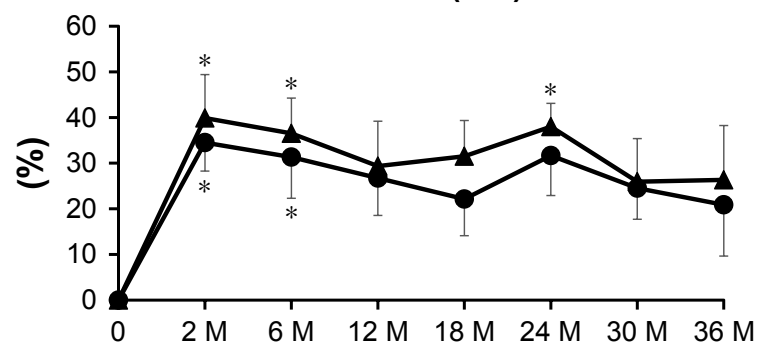

Figure 3 Percent changes of serum tartrate-resistant acid phosphatase (TRACP)-5b (A), urinary cross-linked N-terminal telopeptide of type I collagen (NTX) (B), serum bone alkaline phosphatase (BAP) $(\mathbf{C})$, and serum 25-hydroxyvitamin D (25(OH)D) (D) at I2, 24, and 36 months (M). Circles show the denosumab group and triangles show the combination group.

Notes: Double hashtags indicate a significant difference $(P<0.0 \mathrm{I})$ between the denosumab and combination groups. Single and double asterisks indicate a significant difference $(P<0.05$ and $P<0.01$, respectively) with baseline values. 

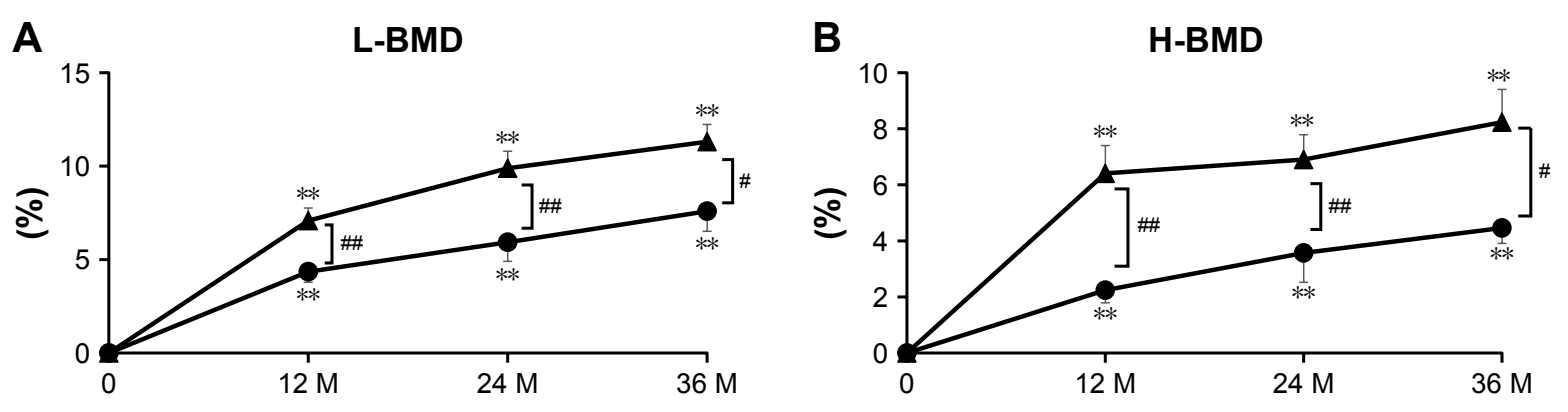

Figure 4 Percent changes in lumbar bone mineral density (L-BMD) (A) and bilateral total hip BMD (H-BMD) (B) at I2, 24 , and 36 months (M).

Notes: Single and double hashtags indicate a significant difference $(P<0.05$ and $P<0.0$, respectively) between the denosumab and combination groups. Double asterisks indicate a significant difference $(P<0.0 \mathrm{I})$ with baseline values.

Similarly, the percent change of H-BMD increased gradually in the denosumab ( $4.5 \%$ increase at 3 years) and combination ( $8.2 \%$ increase at 3 years) groups, with significant differences over baseline at every time point. The percent increase in $\mathrm{H}-\mathrm{BMD}$ was significantly greater in the combination group at years 1, 2, and 3 (Figure 4B).

\section{Indicators of RA state} MMP-3, DAS28-CRP, SDAI, and HAQ-DI

Pretreatment RA state was comparable between the groups, with no remarkable differences in the values of MMP-3, DAS28-CRP, SDAI, or HAQ-DI prior to treatment commencement (Table 1).

\section{Adverse events}

No hypocalcemia, fracture, or other serious adverse events were seen during the 3-year study period.

\section{Discussion}

This study is the first to compare denosumab therapy for 3 years with or without vitamin D and calcium supplementation in patients with OP and RA. The status of serum $25(\mathrm{OH}) \mathrm{D}$ showed persistently high levels throughout the study period in both groups. L-BMD and H-BMD values increased significantly over 3 years in the groups, with those in the combination group rising significantly more. Since no fracture or hypocalcemia occurred in any patient, vitamin D and calcium addition appears to enhance BMD gains, but not necessarily 25(OH)D status, during long-term denosumab therapy for OP with RA.

There have been no reports describing serum $25(\mathrm{OH}) \mathrm{D}$ changes during 3 years of denosumab therapy with or without vitamin D and calcium supplementation in patients with OP and RA. Several investigations have addressed the correlation between serum 25(OH)D status and BMD. ${ }^{19-24}$ Roux et al described a positive association between $25(\mathrm{OH}) \mathrm{D}$ and L-BMD or femoral neck BMD in postmenopausal women treated with ALN. ${ }^{19}$ In Malaysian RA female patients, serum $25(\mathrm{OH}) \mathrm{D}$ levels were low compared with those in healthy controls, with no associations between $25(\mathrm{OH}) \mathrm{D}$ and $\mathrm{BMD},{ }^{20}$ while a negative relationship was identified between 25(OH)D levels and BMD in both sexes in a healthy Iranian population. ${ }^{21}$ In Palestinian postmenopausal OP patients, a positive correlation was reported between $25(\mathrm{OH}) \mathrm{D}$ and L-BMD. ${ }^{22}$ It was noteworthy that all of the OP patients in those studies had taken vitamin D supplementation. ${ }^{19-22}$ We previously found that serum 25(OH)D levels were significantly increased after 3-year BP therapy without additional vitamin D in Japanese postmenopausal OP patients. ${ }^{23}$ On the other hand, serum $25(\mathrm{OH})$ $\mathrm{D}$ had decreased significantly after 4 months of BPs in a Japanese postmenopausal OP cohort. ${ }^{24}$ Thus, it is conceivable that vitamin $\mathrm{D}$ addition may be optional in prolonged BP therapy. In the present denosumab study, serum $25(\mathrm{OH})$ D was persistently increased during 3 years regardless of vitamin $\mathrm{D}$ and calcium supplementation, with significant gains in both L-BMD and H-BMD. On the other hand, Augoulea et al reported that an increase in PTH caused by denosumab therapy was not associated with serum $25(\mathrm{OH})$ D levels. ${ }^{25}$ Serum $1,25(\mathrm{OH})_{2} \mathrm{D}_{3}$ levels are strictly regulated by elevations in $\mathrm{PTH}^{26}$ that are initiated by transient changes in calcium levels as reported previously, ${ }^{27}$ and there is a negative correlation between $25(\mathrm{OH}) \mathrm{D}$ and PTH levels in Brazilians. ${ }^{28}$ Also, Wintermeyer et al have reviewed and reported that $25(\mathrm{OH}) \mathrm{D}$ is metabolized to $1,25(\mathrm{OH})_{2} \mathrm{D}_{3}$ (calcitriol), which is the biologically active form of vitamin D in the kidney. ${ }^{29}$ Thus, it is considered that serum PTH, $1,25(\mathrm{OH})_{2} \mathrm{D}_{3}$, and $25(\mathrm{OH}) \mathrm{D}$ are tightly regulated to one another. Our results suggested that the percent changes of whole PTH and $1,25(\mathrm{OH})_{2} \mathrm{D}_{3}$ in both groups were potentially inhibited due to an increase in $\mathrm{Ca}$ during the study period and that denosumab could increase and maintain $25(\mathrm{OH}) \mathrm{D}$ 
levels regardless of vitamin D and calcium supplementation from an as yet unknown mechanism.

We witnessed that L-BMD and H-BMD were ameliorated at 3 years in both the denosumab $(7.6 \%$ and $4.5 \%$, respectively) and combination ( $11.3 \%$ and $8.2 \%$, respectively) groups compared with baseline values. BMD was more significantly increased during the 3 years in the combination group. The mechanism of this phenomenon is unclear since bone metabolism was more greatly suppressed in the denosumab group. However, $\mathrm{Ca}$ levels in the combination group were more substantially increased during the study period. Kinoshita et al concluded that $\mathrm{Ca}$ was associated with L-BMD gains ${ }^{30}$ since bone metabolism was closely related to calcium metabolism due to calcium storage in the bone (>99\%). ${ }^{31}$ Here, baseline Ca was $9.3 \pm 0.1$ in the denosumab group and $9.2 \pm 0.1$ in the combination group. At 2 years of treatment, the percent change of Ca was $2.2 \%$ in the combination group and $0.9 \%$ in the denosumab group. Thus, BMD might have become more significantly increased in the combination group owing to improvements in $\mathrm{Ca}$ during therapy. Second, as we have previously reported, denosumab might have augmented zinc and iron metabolism to increase BMD in Japanese postmenopausal OP patients. ${ }^{32}$ Similarly to other Japanese OP patients with RA, serum zinc was improved by denosumab therapy, which presumably contributed to ameliorations in BMD. ${ }^{33}$ Here, a more significant increase in serum zinc at 3 years in the combination group might have increased L-BMD and H-BMD more than in the denosumab group, although there were no remarkable differences in serum iron or magnesium between the test groups.

Despite our previous report on percent changes of BAP returning to baseline levels at 2 years of denosumab therapy in OP with RA patients who had received BP pretreatment, ${ }^{34}$ this study revealed continuously strong BAP inhibition for 3 years. This may be due to 1) the patient background differed considerably and 2) the duration of BP use was different, which was 6-7 years here vs approximately 15 years earlier. ${ }^{34}$

The present investigation's main limitation was its sample size and retrospective design. Further assessment of fracture protection will also be necessary to validate our findings.

\section{Conclusion}

This study is the first to show that the addition of vitamin D and calcium supplementation to denosumab in patients with OP and RA exhibited higher serum Ca, zinc, and L-BMD and H-BMD gains over 3 years, suggesting the additive benefits of vitamin D and calcium supplementation on the reduction of fracture risk. This study is also the first to directly compare the long-term effects on serum $25(\mathrm{OH}) \mathrm{D}$ with or without vitamin D and calcium supplementation, both of which revealed a persistent increase during the study period, suggesting that vitamin $\mathrm{D}$ and calcium supplementation might not be necessary for $25(\mathrm{OH}) \mathrm{D}$ status in the same population.

\section{Disclosure}

The authors report no conflicts of interest in this work.

\section{References}

1. Kanis JA. Diagnosis of osteoporosis. Osteoporosis Int. 1997;7(S3): S108-S116.

2. Sims NA, Martin TJ. Coupling the activities of bone formation and resorption: a multitude of signals within the basic multicellular unit. Bonekey Rep. 2014;3:481.

3. Burge R, Dawson-Hughes B, Solomon DH, Wong JB, King A, Tosteson A. Incidence and economic burden of osteoporosis-related fractures in the United States, 2005-2025. J Bone Miner Res. 2007; 22(3):465-475.

4. Kvien TK, Haugeberg G, Uhlig T, et al. Data driven attempt to create a clinical algorithm for identification of women with rheumatoid arthritis at high risk of osteoporosis. Ann Rheum Dis. 2000;59(10):805-811.

5. Lodder MC, Haugeberg G, Lems WF, et al; Oslo-Truro-Amsterdam (OSTRA) Collaborative Study. Radiographic damage associated with low bone mineral density and vertebral deformities in rheumatoid arthritis: the Oslo-Truro-Amsterdam (OSTRA) collaborative study. Arthritis Rheum. 2003;49(2):209-215.

6. Haugeberg G, Uhlig T, Falch JA, Halse JI, Kvien TK. Bone mineral density and frequency of osteoporosis in female patients with rheumatoid arthritis: results from 394 patients in the Oslo County Rheumatoid Arthritis register. Arthritis Rheum. 2000;43(3):522-530.

7. Dimitroulas T, Nikas SN, Trontzas P, Kitas GD. Biologic therapies and systemic bone loss in rheumatoid arthritis. Autoimmun Rev. 2013;12(10): 958-966.

8. Holick MF. Vitamin D deficiency. N Engl J Med. 2007;357(3): 266-281.

9. Morris HA. Vitamin D activities for health outcomes. Ann Lab Med. 2014;34(3):181-186.

10. Lips P, Gielen E, van Schoor NM. Vitamin D supplements with or without calcium to prevent fractures. Bonekey Rep. 2014;3:512.

11. Ebeling PR. Vitamin D and bone health: Epidemiologic studies. Bonekey Rep. 2014;3:511.

12. Tan LM, Long TT, Guan XL, et al. Diagnostic Value of Vitamin D Status and Bone Turnover Markers in Rheumatoid Arthritis Complicated by Osteoporosis. Ann Clin Lab Sci. 2018;48(2):197-204.

13. Black DM, Bauer DC, Schwartz AV, Cummings SR, Rosen CJ. Continuing bisphosphonate treatment for osteoporosis - for whom and for how long? N Engl J Med. 2012;366(22):2051-2053.

14. Bone HG, Wagman RB, Brandi ML, et al. 10 years of denosumab treatment in postmenopausal women with osteoporosis: results from the phase 3 randomised FREEDOM trial and open-label extension. Lancet Diabetes Endocrinol. 2017;5(7):513-523.

15. Nakamura Y, Suzuki T, Kamimura M, et al. Vitamin D and calcium are required at the time of denosumab administration during osteoporosis treatment. Bone Res. 2017;5:17021.

16. Soen S. New Diagnostic Criteria and Guidelines on Osteoporosis. Diagnostic criteria for primary osteoporosis: year 2012 revision. (Article in Japanese). Clin Calcium. 2014;24:323-329.

17. van der Linden MP, Knevel R, Huizinga TW, van der Helm-van Mil AH. Classification of rheumatoid arthritis: comparison of the 1987 American College of Rheumatology criteria and the 2010 American College of Rheumatology/European League Against Rheumatism criteria. Arthritis Rheum. 2011;63(1):37-42. 
18. Kamimura M, Taguchi A, Nakamura Y, et al. Pretreatment of daily teriparatide enhances the increase of bone mineral density in cortical bones by denosumab therapy. Ther Clin Risk Manag. 2018;14:637-642.

19. Roux C, Binkley N, Boonen S, et al; FOCUS-D Investigators. Vitamin D status and bone mineral density changes during alendronate treatment in postmenopausal osteoporosis. Calcif Tissue Int. 2014;94(2):153-157.

20. Wong TH, Gupta ED, Radhakrishnan AK, Gun SC, Chembalingam G, Yeap SS. Effects of 25-hydroxyvitamin D and vitamin D-binding protein on bone mineral density and disease activity in Malaysian patients with rheumatoid arthritis. Int J Rheum Dis. 2018;21(5):992-1000.

21. Khashayar P, Aghaei Meybodi HR, Rezai Hemami M, Keshtkar A, Dimai HP, Larijani B. Vitamin D status and its relationship with bone mineral density in a healthy Iranian population. Rev Bras Ortop. 2016;51(4):454-458.

22. Kharroubi A, Saba E, Smoom R, Bader K, Darwish H. Serum 25-hydroxyvitamin D and bone turnover markers in Palestinian postmenopausal osteoporosis and normal women. Arch Osteoporos. 2017; 12(1):13.

23. Nakamura Y, Uchiyama S, Kamimura M, Ikegami S, Komatsu M, Kato H. Increased Serum $25(\mathrm{OH}) \mathrm{D}_{3}$ Levels in Post-Menopausal Japanese Women with Osteoporosis after 3-Year Bisphosphonate Treatment. Tohoku J Exp Med. 2017;242(3):241-246.

24. Kamimura M, Uchiyama S, Nakamura Y, Ikegami S, Mukaiyama K, Kato H. Short-term bisphosphonate treatment reduces serum $25(\mathrm{OH})$ vitamin $\mathrm{D}_{3}$ and alters values of parathyroid hormone, pentosidine, and bone metabolic markers. Ther Clin Risk Manag. 2017;13:161-168.

25. Augoulea A, Tsakonas E, Triantafyllopoulos I, et al. Comparative effects of denosumab or bisphosphonate treatment on bone mineral density and calcium metabolism in postmenopausal women. J Musculoskelet Neuronal Interact. 2017;17(1):444-449.
26. Fleet JC. The role of vitamin $\mathrm{D}$ in the endocrinology controlling calcium homeostasis. Mol Cell Endocrinol. 2017;453:36-45.

27. Nakamura $Y$, Kamimura M, Ikegami S, et al. Changes in serum vitamin D and PTH values using denosumab with or without bisphosphonate pre-treatment in osteoporotic patients: a short-term study. BMC Endocr Disord. 2015;15:81.

28. Martins JS, Palhares MO, Teixeira OC, Gontijo Ramos M. Vitamin D Status and Its Association with Parathyroid Hormone Concentration in Brazilians. J Nutr Metab. 2017;2017:9056470.

29. Wintermeyer E, Ihle C, Ehnert S, et al. Crucial Role of Vitamin D in the Musculoskeletal System. Nutrients. 2016;8(6):E319.

30. Kinoshita M, Ishijima $M$, Kaneko $H$, et al. The increase in bone mineral density by bisphosphonate with active vitamin $\mathrm{D}$ analog is associated with the serum calcium level within the reference interval in postmenopausal osteoporosis. Mod Rheumatol. Epub 20189 Mar.

31. Favus MJ, Goltzman D. Regulation of calcium and magnesium. In: Rosen CJ, editor. Primer on the Metabolic Bone Diseases and Disorders of Mineral Metabolism. 8th ed. Hoboken, NJ: John Wiley \& Sons; 2013:172-179.

32. Suzuki T, Nakamura Y, Kato H. Changes of Bone-Related Minerals during Denosumab Administration in Post-Menopausal Osteoporotic Patients. Nutrients. 2017;9(8):E871.

33. Suzuki T, Nakamura Y, Kato H. Determination of serum bone-related minerals during denosumab treatment in osteoporosis patients with rheumatoid arthritis. Clin Nutr ESPEN. 2018;26:53-56.

34. Nakamura Y, Suzuki T, Kato H. Denosumab significantly improves bone mineral density with or without bisphosphonate pre-treatment in osteoporosis with rheumatoid arthritis: Denosumab improves bone mineral density in osteoporosis with rheumatoid arthritis. Arch Osteoporos. 2017;12(1):80.
Therapeutics and Clinical Risk Management

\section{Publish your work in this journal}

Therapeutics and Clinical Risk Management is an international, peerreviewed journal of clinical therapeutics and risk management, focusing on concise rapid reporting of clinical studies in all therapeutic areas outcomes, safety, and programs for the effective, safe, and sustained use of medicines. This journal is indexed on PubMed Central, CAS,

\section{Dovepress}

EMBase, Scopus and the Elsevier Bibliographic databases. The manuscript management system is completely online and includes a very quick and fair peer-review system, which is all easy to use. Visit http://www.dovepress.com/testimonials.php to read real quotes from published authors. 